\title{
The influence of semantic relevance on the discernment of product appearance and function
}

\author{
Ching-Yi Wang ${ }^{1 *}$ (ID and Yu-Er Lin²
}

\begin{abstract}
Background: This study investigated the impact of semantic relevance on the ability to comprehend the appearance and function of a product, as presented in images.

Methods: The images used the constructs of Simile, Metaphor and Analogy to correspond to congruent, related and incongruent semantic structures, and measured the amplitude of Event-Related Potentials (ERPs) to compare these images with Landscape images. Sixteen participants with design-related educational backgrounds were invited to join in the ERP experiment.

Results: The results found that the image depicting the Metaphor showed a stronger N600 amplitude in the right anterior region of the brain than the Landscape image and the Analogy image induced a stronger N600 effect in the left anterior and right anterior part of the brain than the Landscape image. However, the Simile image did not trigger the N600. The N600 was triggered when the meaning of the Metaphor and Analogy being presented could not be understood. This indicates that a greater processing effort to comprehend them than was required for Simile. Analogy has a wider N600 distribution than Metaphor in the anterior area, suggesting that Analogy would require higher-level thinking processes and more complex semantic processing mechanisms than Metaphor.
\end{abstract}

Conclusions: The $\mathrm{N600}$ implicated that an assessment method to detect the semantic relationship between appearance and function of a product would assist in determining whether a symbol was suitable to be associated with a product.

Keywords: Event-related potentials (ERPs), N600, Semantic, Figurative product, Metaphor

\section{Background}

\section{Figurative design}

A product's design says something about the designer and is therefore a form of communication between the designer and the user; the designer uses symbols that can be understood by potential users to describe the various functions of the product. One of the senses people use to identify and comprehend their external environment is

\footnotetext{
*Correspondence: catincar@gmail.com

1 Present Address: Department of Creative Product Design, Asia University, No. 500, Lioufeng Rd., Wufeng, Taichung City 41354, Taiwan Full list of author information is available at the end of the article
}

sight but their judgment and their interpretation of what they are seeing will be influenced to a certain extent by their knowledge and experience [1]. The use of Metaphor in design is widely used in product advertising. The abstract symbols designers use to enhance consumers' perception of the product will become associated with the product and its design. However, it is not certain that every user will interpret the symbols in the same way or as intended. For example, the butterfly chair which designed by Sori Yanagi is such that when seen from the front, the chair looks like a butterfly. However, if the Metaphor of a butterfly is used, the person who wants to sit 
on the chair may find it difficult to associate the image of a butterfly with that of a chair. This has to do with semantic cognition.

A product can be described in terms of its practical functions, but an additional layer of meaning can be added by the use of Metaphor which may affect the user's perception of the function of the product. Whether people have a background in industrial design or they have no design experience, product recognition is higher than that of design recognition which in turn, is higher than the recognition of correlative meaning [1]. Therefore, if the symbol used to describe the product is not clear or is too abstract, users may well misinterpret the function of the product or its actual shape.

According to Lin and Huang's [1] comprehensive analysis of the semantics used in describing a product, Metaphorical design can be divided into five categories: Metaphor, Simile, allegory, metonymy, and Analogy. This study found that when these are ranked, Simile has the highest recognition rate, followed by Metaphor and Analogy. Metonymy and allegory have the lowest recognition rate. Therefore, this study uses Simile, Metaphor and Analogy as stimuli because they are easily recognized and differences can be noted. Different levels of semantic relevance are offered in images of the product and the functional relevance compared in order to study the extent to which participants associate the semantic structures with the product. Based on Lin andHuang's [1] analysis of the semantics, the meaning of these three categories is explained below.

(a) Simile: Rhetoric is in the form of "A is like B". The product uses the obvious appearance as the symbol of the product. It aims to directly indicate the meaning with no hidden or clear instructions. The design is straightforward and clear as a Simile. Figure 1 is an umbrella stand. The shape uses an umbrella-like outer frame to replace the umbrella function.

(b) Metaphor: Rhetoric is in the form of "A is B". The product and borrowed symbol have similarities in a certain feature (for example: form, color, and characteristic, etc.). Figure 2 is the Kataguruma chair. The appearance is based on piggyback rides as the symbol of the product. Riding on the shoulders is similar to sitting on a chair. There is a common characteristic of "sitting" between the two. When using the product, it will awaken the memory of riding on the shoulder as a child.

(c) Analogy: Rhetoric is in the form of "A is not B". It means that there is no direct connection between the product and the borrowed symbol. It associates the meaning of a product with a certain characteristic or situation. Figure 3 shows the Peakco vase,

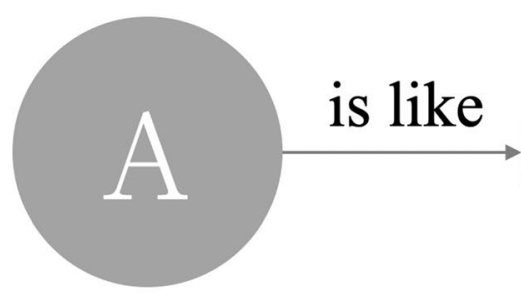

umbrella shape provide the function of placing umbrella

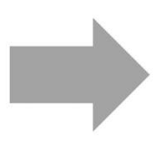

Fig. 1 Simile uses "A is B" form and product example (image retrieved from [2])

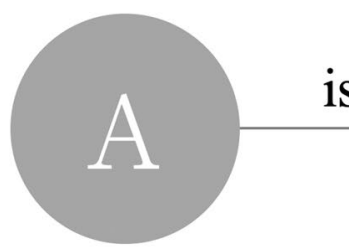

sitting on the shoulders
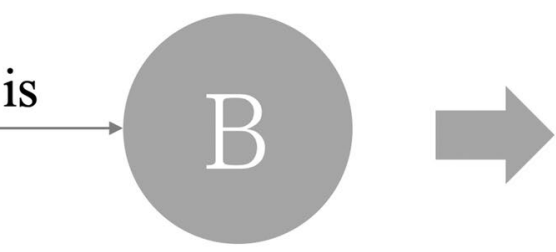

the pose of piggyback rides

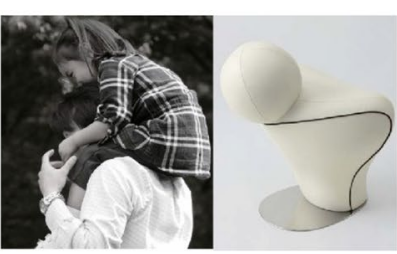

chair

Fig. 2 Metaphor uses "A is like B" form and product example (image retrieved from [3]) 


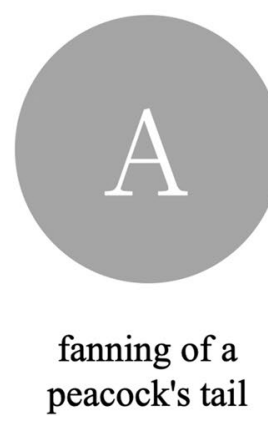

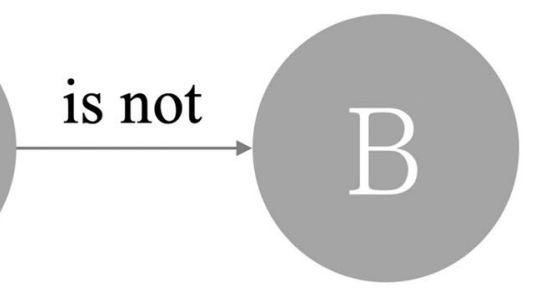

flowers replace

peacock feathers
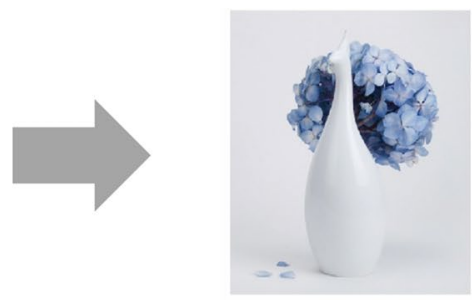

vase

Fig. 3 Analogy uses "A is not B" form and product example (image retrieved from [4])

Table 1 The logic of card sorting

\begin{tabular}{llll}
\hline Category & Simile & Metaphor & Analogy \\
\hline Example & Umbrella stand & Chair & Vase \\
$\begin{array}{l}\text { Appearance } \\
\text { Borrowed symbols } \\
\text { standing }\end{array}$ & Umbrella & Piggyback rides & Peacock \\
$\begin{array}{l}\text { Semantic relevance } \\
\text { Easy }\end{array}$ & Congruent & Related & Difficult
\end{tabular}

which uses the shape of a peacock to represent the concept of vases and flowers to interpret the functions of the product. However, simply presenting the symbol of a peacock without feathers cannot constitute the association of a vase. Connecting the concept of "flower" with the attribute of "fanning of a peacock's tail" can form a complete association of vases.

Table 1 shows the types of semantic associations between product shape and function in the above three categories. The degree of semantic relevance to these three categories is Simile $>$ Metaphor $>$ Analogy. The degree of semantic comprehension for these three categories is Simile>Metaphor $>$ Analogy. This means that products with higher semantic relevance are easier to understand. Therefore, these three different semantic represent congruent semantic, related semantic, and incongruent semantic, respectively.

\section{ERP}

People respond emotionally to what they see-this psychological response is closely related to physiological stimuli [5]. Brain waves can be used to measure the psychological reaction to a visual stimulus as different cognitive activities will stimulate different regions in the brain, while the intensity of the potential changes and the distribution will be different. This knowledge can be used to understand and compare the participant's cognitive processes. Event-Related Potentials (ERPs) (a category of psychophysiology) are electrophysiological signals that can be identified by electroencephalography (EEG): a psychological reaction to a stimulus directly triggers a neural response in the brain. The advantage of an ERP is its high resolution-measurement technology that identifies subtle changes in brain potential over a short period of time. The ability to rapidly record the brain's response to stimuli without the need for external responses means that the cognitive processes of the participants can be studied and inferences made about their responses according to different patterns of neural activity.

\section{N400}

The N400 (which is a component of ERP) is commonly used to study the principles of language processing. This is a negative waveform that can be measured in the brain after the stimulus has been presented for 300 to $500 \mathrm{~ms}$. It is generally believed that the $\mathrm{N} 400$ is related to the extraction of semantic messages in long-term memory and can be used to reflect semantic processing. Some studies have suggested that the comprehension of Metaphor can be measured by the N400 response [6] but there can be difficulties with this in terms of the semantic context of the Metaphor (for example, if the semantic context is weak or absent). In the recording of Metaphors, the N400 manifests different amplitudes according to the degree to which the Metaphor is comprehended and whether it is presented within a recognized semantic context. Coulson and Van Petten [7] found that literal language and Metaphorical language are processed in the same way but that Metaphorical language requires more processing than literal language. Ortiz et al. [8] 
believe that the use of visual Metaphors can produce the same effect as text, and that Metaphorical images can encourage a stronger $\mathrm{N} 400$ response than more familiar images. With familiar images, the $\mathrm{N} 400$ response indicated activity in both the left and right hemispheres of the brain, with more in the left side of the brain,when mixed-Metaphor pictures were presented, there was greater activity in the right side of the brain [9-12]. The semantic processing mechanism of familiar images and that of Metaphorical images indicated that mixed Metaphors are different. Because Metaphors use unexpected language, the brain produces more asymmetric activity and stronger current density than when regular language is used.

\section{N600}

The N600 is a negative wave that is triggered $600-800 \mathrm{~ms}$ after the stimulus of inconsistent semantic structures [13-15]. Shibata et al. [16] found that this positive component is similar to the N400 component and can be considered as a second $\mathrm{N} 400$ reaction in the later period. Many studies have shown that the N600 is triggered by practical experience and logical thinking or comprehension of the rules as well as inconsistent stimuli such as those provided by humor and entertainment $[15,17]$. Therefore, the N600 is often triggered in the detection of humor or jokes, mainly in the observation of N270, N400, N600-800, and even $1500 \mathrm{~ms}$ slow waves [14, 17-19].

Samson et al. [20, 21] argue that to comprehend humor, people need to apply the cognitive process of organizational thinking, have insight, and the ability to successfully resolve ambiguous sentences. This is because the understanding of incongruent structures requires more coherent construction and greater psychological manipulation and context reorganization [20] (Chan et al. 2012). Coulson and Kutas [22] indicated that inconsistent stimuli prompted two phases: an early phase where inconsistent stimuli prompted the $\mathrm{N} 400$ detection phase, and a later phase where the comprehension of inconsistent stimuli triggered 500-900 ms slow waves. Wang et al. [19], in their study of paintings showing facial humor, found that facial deformation evoked significant differences in the N270, N400, and N600-800 bands, and were indeed related to cognitive dissonance theory.

\section{Summary}

Based on the above ERP literature, N400 component is the response to an inconsistent stimulus; N600 is triggered by the process of a person perceiving an inconsistency and having to re-evaluate the language structure in order to find a solution. This study posits that the semantic processing process of a product is similar to cognitive semantics. Previous studies focused on the relevance of context in the semantics of cognition, such as the semantic similarity of pronunciation (cough-rough), category (cat-dog) and vision (rough-dough). Semantic meaning in both cognition and design explores the "relevance" of semantic meaning, which is based on contextual relevance, and compares the common attributes between them. The difference lies in the input stimulus form. The "meaningful" stimulus may produce ERP effects no matter whether what the non-verbal and verbal forms of text, pictures, sound, and video. Therefore, product pictures as a stimulus should induce ERP effects. The samples of this ERP experiment used actual products to visually explore the correlation between product appearance and category. Based on the relevance of Simile, Metaphor and Analogy in the relationship (see Table 1) between the given semantics and the function of the product the order of the semantic relevance was congruent, related, and incongruent, respectively. According to the degree of semantic association, this study assumes that Analogy might induce the strongest N600 amplitude, followed by the Metaphor. The congruent semantics of Simile should not induce an N600 effect.

\section{Methods \\ Participants}

Because the research involves relevant content such as product design, design history, and product knowledge, the participants were required to have a design background. Sixteen participants (ten males, six females; mean age $=23.56$ years, $\operatorname{Std}=1.32$ years) were invited to participate in the experiment. All participants had design-related university degrees, were right-hand dominant and had no presenting adverse conditions such as visual impairment or brain injury. The experimental standards of the study were approved by the China Medical University \& Hospital Research Ethics Center of Taiwan (CRREC-109-027). Written informed consent was obtained from all participants prior to participation.

\section{Materials \\ Simile, Metaphor, and Analogy stimulus}

Four experts (male, mean age $=52.75$ years, std $=5.9$ ) with over 20 years of teaching and product-design experience were invited to select samples. In the logic of card sorting (see the Table 1), experts judge the semantic comprehension of the product according to the degree of conversion and relevance between the appearance of the product and the borrowed symbol for each category (such as Simile, Metaphor, and Analogy).

The process of card sorting is divided into two stages. In the first stage (Fig. 4a), 160 images were repeatedly divided into 110,129 , and 84 items for the features of the Simile, Metaphor, and Analogy categories. These cards 


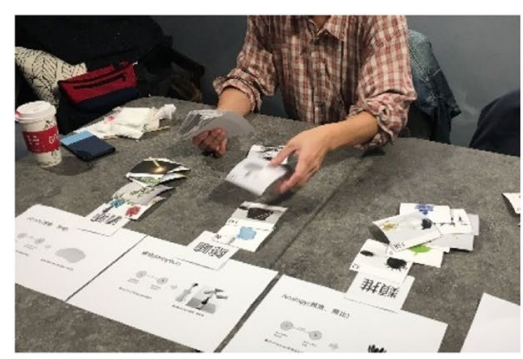

(a)
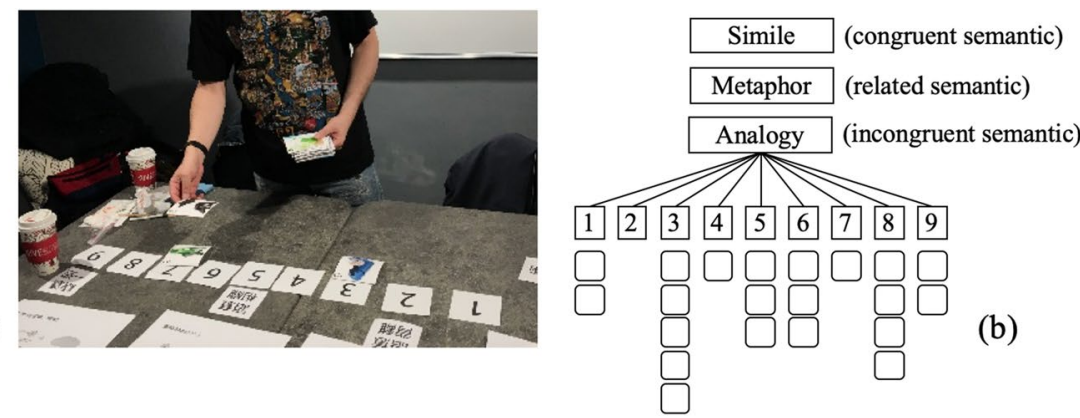

Fig. 4 Card sorting: a The first step: 160 cards are repeatedly divided into Simile, Metaphor and Analogy categories, and $\mathbf{b}$ the second step: each category is based on 9 scales of semantic distance ( $1=$ extremely difficult to understand, $9=$ extremely easy to understand) for classification. These three categories for semantic understanding represent congruent semantic, related semantic, and incongruent semantic, respectively

Table 2 Classification results of simile, metaphor and analogy

\begin{tabular}{llll}
\hline & Simile & Metaphor & Analogy \\
\hline The original number & 160 & 160 & 160 \\
The number of first grouping & 110 & 129 & 84 \\
The number of second grouping & 40 & 40 & 40 \\
Mean & 4.63 & 5.19 & 3.71 \\
SD & 3.60 & 3.64 & 3.81 \\
\hline
\end{tabular}

permit more than two categories at this stage. In the second stage (Fig. 4b), each category is classified according to 9 scales of semantic distance $(1=$ extremely difficult to understand, $9=$ extremely easy to understand). The number of pictures in each scale differs or is vacant. If the sample has more than two categories, the experts will discuss and decide which category it belongs to. A total of 120 images were screened (see the "Appendix 1"). The averages of the three categories (see the Table 2) were $4.63,5.19$, and 3.71 , respectively. If the expert is not clear about the content of the picture during the classification process, the researcher will explain it to the expert but will not guide him to make a choice.

\section{Neutral stimulus}

In addition, 40 colorful neutral images (Fig. 5) were selected from the Nencki Affective Picture System (NAPS), including: Landscapes, animals, plants, artifactual objects, buildings, roads, and humans [23-26]. These stimuli provided a baseline for comparisons among Simile, Metaphor, and Analogy stimulus.

\section{ERP recording}

The equipment used in this study was a 32-channel Bluetooth wireless physiological feedback device: NeXus-32

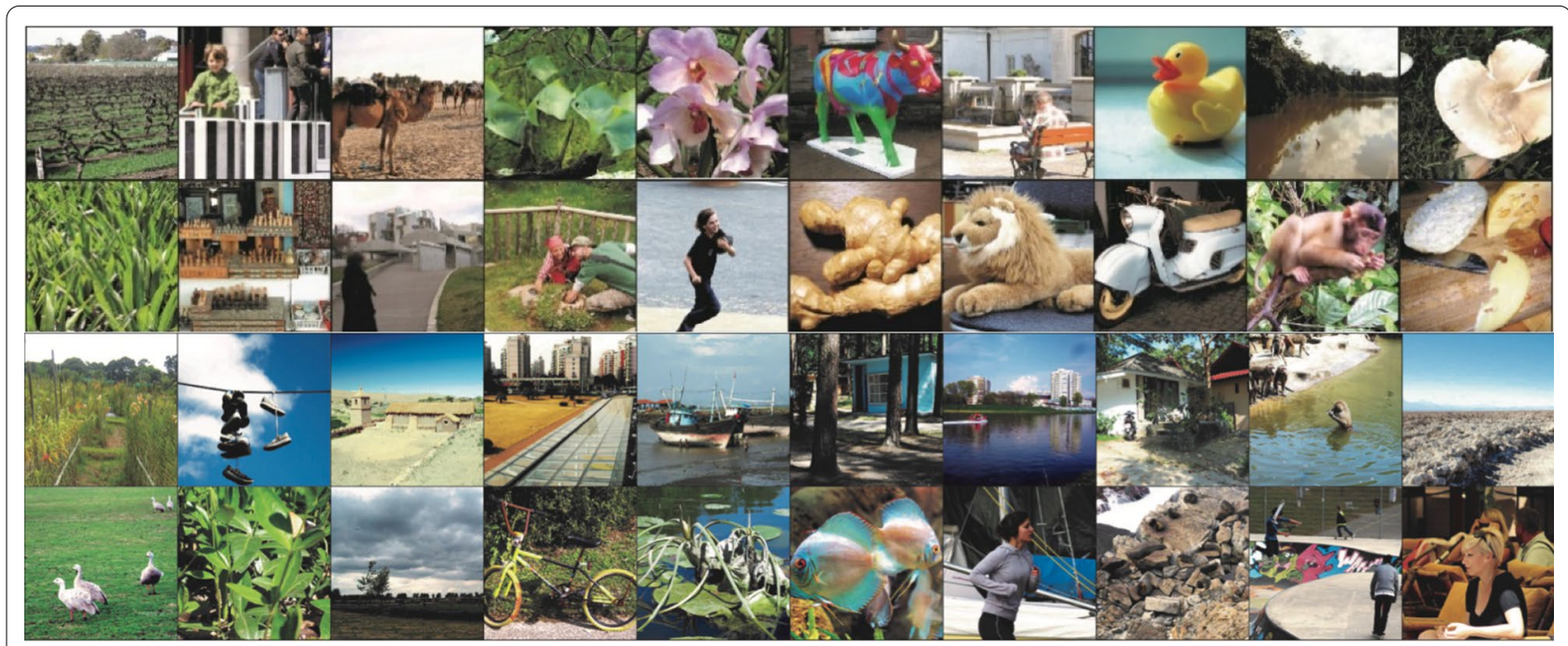

Fig. 5 Neutral stimulus 
(Mind Media, The Netherlands). All channels were referenced to an electrode located between $\mathrm{Fz}$ and $\mathrm{FCz}$, and were re-referenced off-line to the average of the two mastoid electrodes [27-30]. The electrode impedance was $5 \mathrm{k} \Omega$, the brain wave recording frequency was $250 \mathrm{~Hz}$, and the data was filtered at $0.5-60 \mathrm{~Hz}$ [31]. Noise was filtered out by means of BioTrace + software, with the maximum amplitude (over $80 \mu \mathrm{V}$ ) eye movement signal per signal [32,33], and frontal muscle signal with frequency greater than $20 \mathrm{~Hz}$ [34] was used as the standard. A baseline correction ( -100 to $0 \mathrm{~ms}$ ) was applied. The brain wave data elicited in the experiment was analyzed and processed using WINEEG software. The continuously recorded brain waves were segmented for a total period of 0-1000 ms and the EEG data was converted to ERP format. The time windows for the N400 and N600 were $300-500 \mathrm{~ms}$ and $600-748 \mathrm{~ms}$, respectively. Then, the brainwave segments of each participant were overlaid and averaged. Finally, the brainwave amplitude of all the participants was averaged for statistical analysis.

\section{Procedure}

Participants were fitted with an elastic electrode cap and then seated in an electrically isolated chamber. The participants were asked to sit approximately $70 \mathrm{~cm}$ from the screen. After confirming that the participants clearly understood the process, the experiment began with a total of 160 picture-word combinations, including figurative products (Simile, Metaphor, and Analogy) (see the "Appendix 2") and neutral images. Each word in Chinese was paired with a picture. In order for the meaning of the presented words to be easily understood by the participants and for them to quickly enter the topic, the naming method of each word must be simple and 2-4 Chinese words. Among the words, the 120 trials of prime words for the Simile, Metaphor, and Analogy images appeared as the "product's category" (i.e., "椅子(chair)", "燈(lamp)", "廚具(kitchenware)", "文具(stationery) ", etc.). There were 62 product categories in total. In addition, the 40 trials of prime words for the neutral images showed "風 景(Landscape)".

Figure 6 shows the ERP Procedure. Each trial began by showing a fixation point at the center of the screen for $1000 \mathrm{~ms}$. After the fixation point had disappeared, the prime word in Chinese (i.e., "椅子(chair)") was presented for $1000 \mathrm{~ms}$, followed by a blank screen for $1000 \mathrm{~ms}$. The target then appeared and remained on

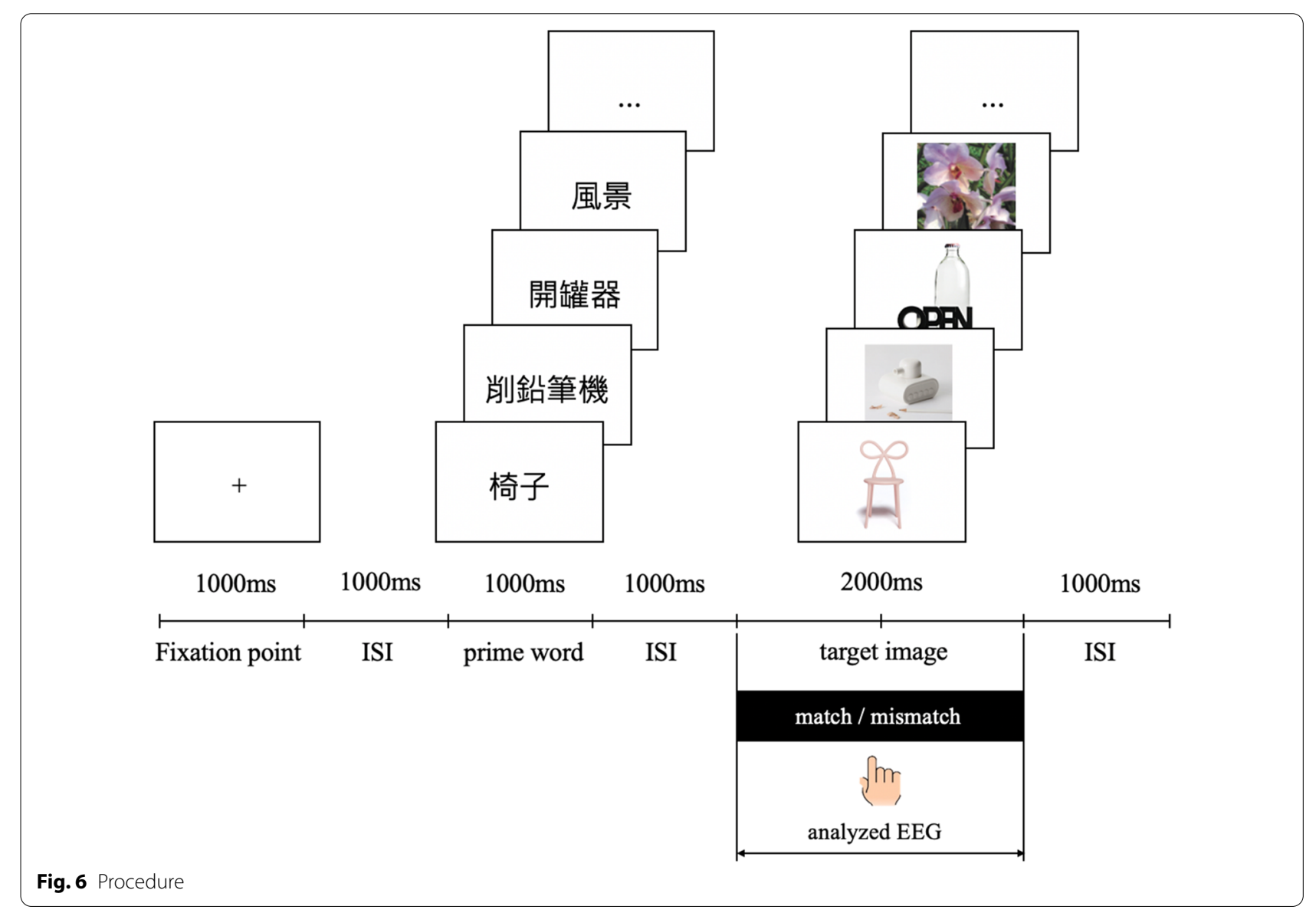


the screen for $2000 \mathrm{~ms}$. During this period, the participants were required to judge whether the symbol of the shape (appearance) of the target matched the product category expressed in the preceding word. The target is a chair with a butterfly-shaped back, and its appearance differs from that of ordinary chairs. The participants compared typical chair types they imagined (i.e., such as four legs and a platform for sitting) to compare with the various products they saw in this experiment. Participants were told to press a button with the index finger of one hand to register a response match, and to register non-matches with the index finger of the opposite hand. To avoid their dominant hand influencing the match/mismatch response, the assignment of the fingers to the response categories was counterbalanced across participants: half of the participants used their right index finger to input "match", and the other participants used it to input "mismatch". The screen then went blank for $1000 \mathrm{~ms}$, and the next trial started. There was a ten-minute break after 160 trials. Each word and image were presented once in random order. The EEG signal was recorded throughout the experiment. Among the results, the analyzed EEG was extracted from the interval of target appeared and remained on the screen for $2000 \mathrm{~ms}$.

\section{ERP data analysis}

The selection of the electrode sites (F3, Fz, F4, C3, Cz, and C4) (Fig. 7) was based on previous studies [35-38].
Krawczyk [39] found that N600 mainly appears in the prefrontal cortex. Figure 8 shows the ERP waveforms of $\mathrm{F} 3, \mathrm{Fz}, \mathrm{F} 4, \mathrm{C} 3, \mathrm{Cz}$ and $\mathrm{C} 4$. The waveform direction of all stimuli developed at approximately $80 \mathrm{~ms}$ and became negative at about $600 \mathrm{~ms}$. The N600 appeared between 600 and $748 \mathrm{~ms}$, peaking at $684 \mathrm{~ms}$ (Fig. 8). Therefore, the N600 component was selected and the time window was averaged at this interval (yellow area) after target onset. This section was based on recommendations made in previous N600 research $[17,19,22]$. However, there is no obvious 400 waveform over the $300-500 \mathrm{~ms}$ time period after stimulus onset. Several previous N400 studies [4042] also informed the selection of the N400 measurement interval.

Repeated measures ANOVA using SPSS statistics 24 software was used to understand whether there was a difference in ERP based on three different semantic categories between product appearance and borrowed symbols, including congruent semantic, related semantic, and incongruent semantic. This experiment was the withinsubjects study design, i.e., the same person tests all the conditions.

MANOVA analysis were divided into two steps. The first three-way MANOVA analysis factor included the "category" (Simile, Metaphor, Analogy, and Landscape), and the electrode sites (Fig. 9) of the "anterior-central" and "left-medial-right" positions (left anterior: F3; medial anterior; Fz, right anterior: F4; left central: C3; medial central: $\mathrm{Cz}$; right central: $\mathrm{C} 4)$. The

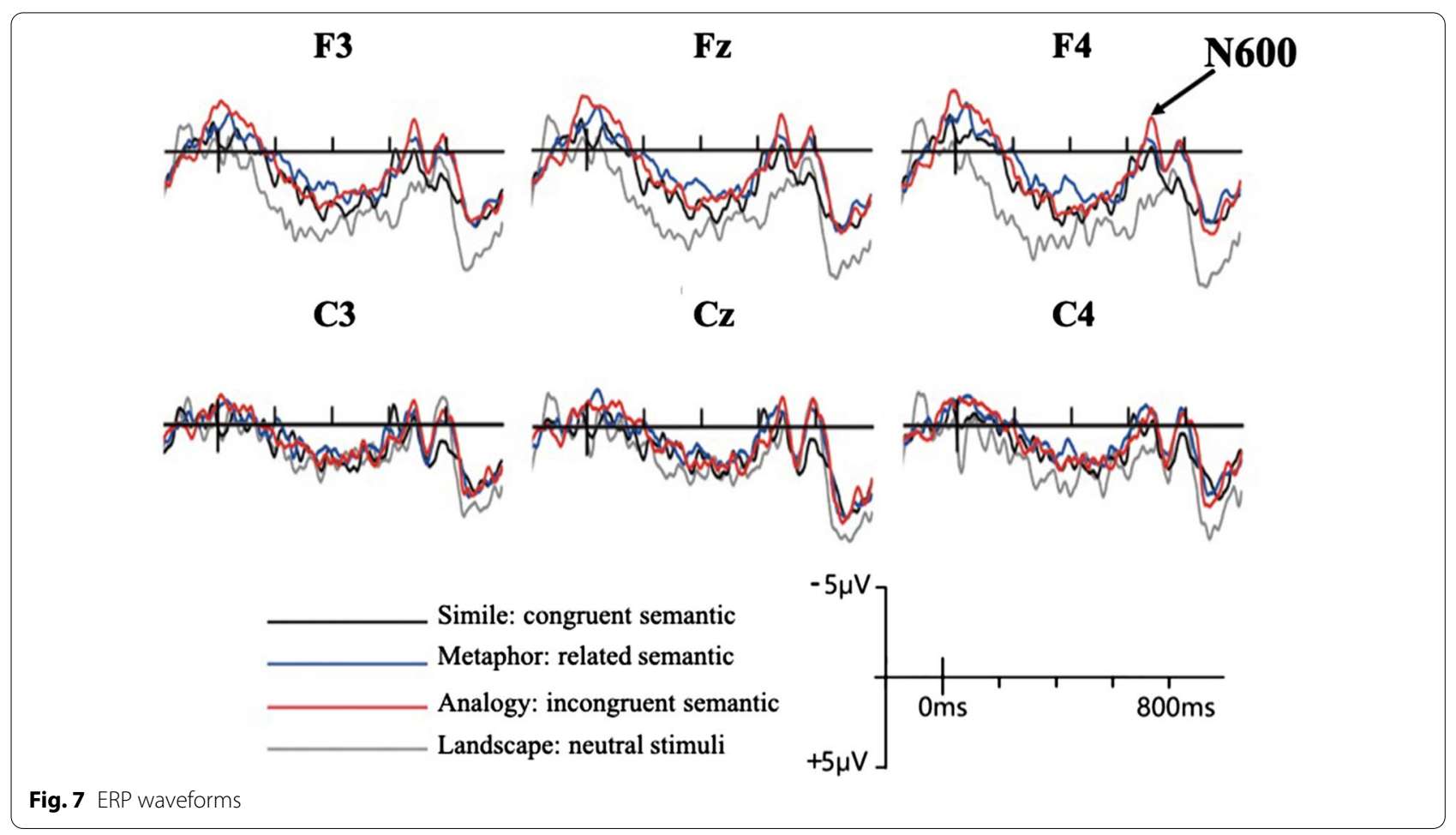




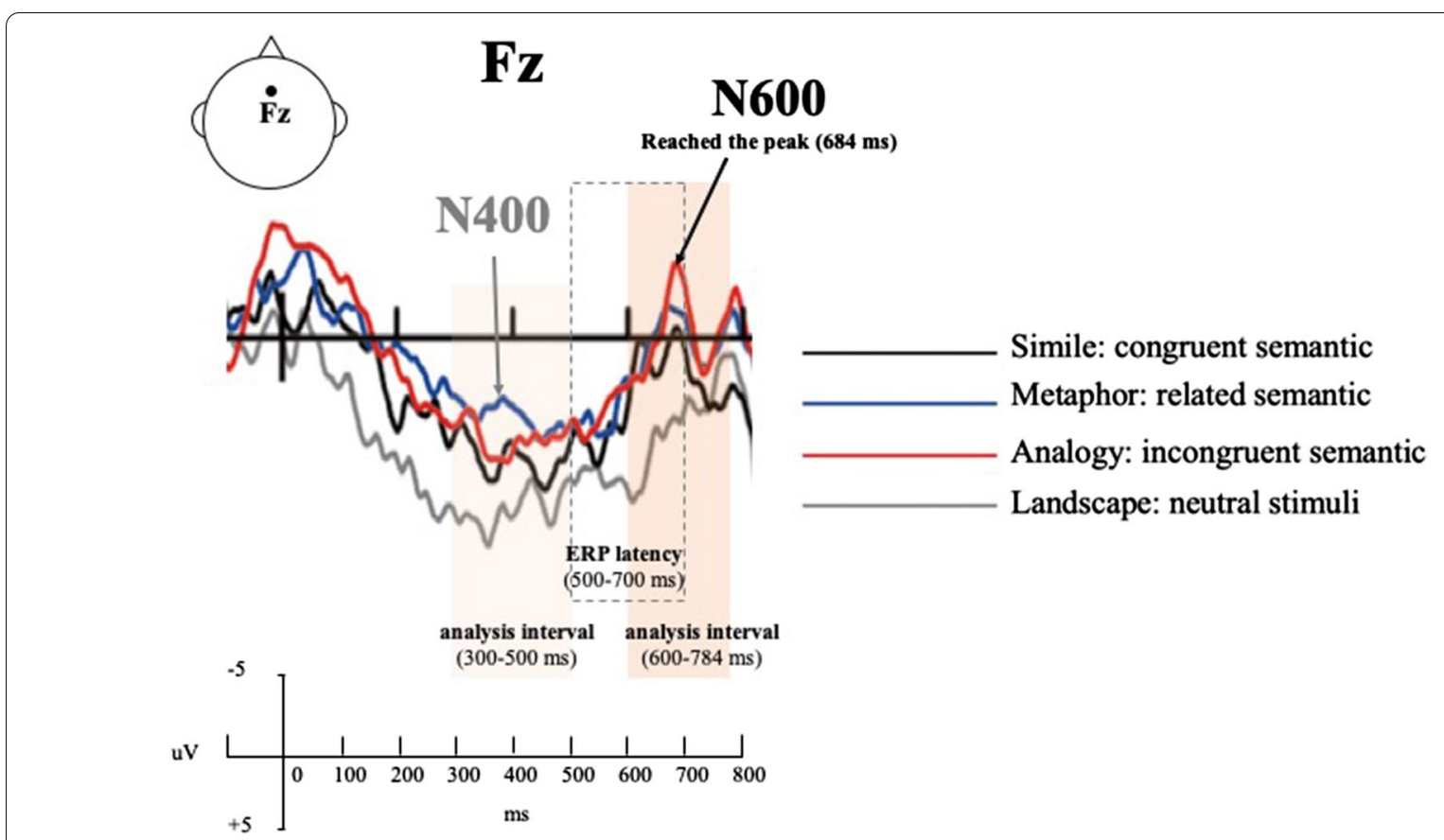

Fig. 8 Ground average ERP: F3, Fz, F4, C3, Cz, and C4 electrode sites were selected and analyze N400 (300-500 ms) and N600 (600-748 ms) effects

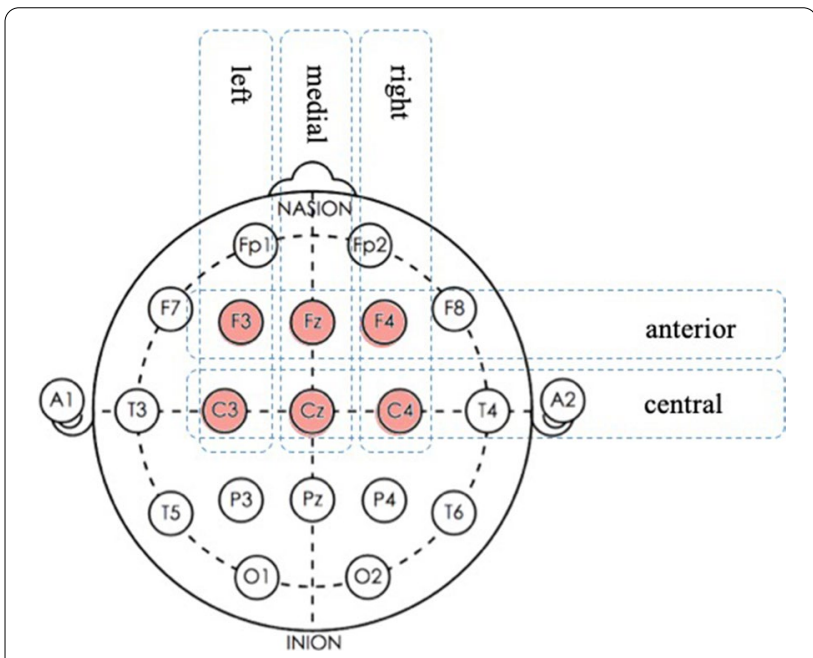

Fig. 9 The six electrode sites were divided into "anterior-central" and "left-medial-right" positions

Greenhouse-Geisser correction for non-sphericity was applied where appropriate. Further analysis was used the paired sample $t$-test to ensure any potentially important factors when the interaction was significant.

\section{Results}

\section{Behavioral results}

Table 3 displays the percentages of match responses for Simile, Metaphor, Analogy, and Landscape: $82.19 \%$,
Table 3 Behavioral results for four categories in the semantic judgment tasks (standard deviation of mean in parentheses)

\begin{tabular}{lll}
\hline Prime word-target image & Match response & \\
\hline Simile & $82.19 \%$ & $(5.15 \%)$ \\
Metaphor & $73.28 \%$ & $(6.10 \%)$ \\
Analogy & $55.63 \%$ & $(8.29 \%)$ \\
Landscape & $99.22 \%$ & $(1.51 \%)$ \\
\hline
\end{tabular}

$73.28 \%, 55.63 \%$, and $99.22 \%$, respectively. The levels of difficulty of the semantic matching task were Landscape, Simile, Metaphor, and Analogy in order from the easiest to the most difficult. The behavioral results of the four categories verified the semantic associations between product shape and function in the forenamed Table 1.

\section{N400 (300-500 ms) effect}

Table 4 shows the average amplitudes of N400 for Simile, Metaphor, Analogy, and Landscape: 1.70, 1.08, 1.88, and $1.40 \mu \mathrm{V}$, respectively. In terms of numerical values, the amplitude of $\mathrm{N} 400$ on the four categories from largest to smallest were Analogy, Simile, Landscape, and Metaphor.

Table 5 presents the overall result of MANOVA analysis of N400 for the category, anterior-central, and leftmedial-right factors. Only the "anterior-central" position factor has the main effect $(\mathrm{F}[1,30]=5.93, p=0.03, \varepsilon=1)$. However, there were no interactions between the "category" $\mathrm{x}$ "anterior-central" position factors $(\mathrm{F}[3,45]=1.03$, 
$p=0.39)$ and "category" $\mathrm{x}$ "left-medial-right" position factors $(\mathrm{F}[6,90]=2.29, p=0.07)$.

\section{N600 (600-748 ms) effect}

Table 6 shows the average amplitudes of N600 for Simile, Metaphor, Analogy, and Landscape: 0.63, 0.10, 0.03, and $1.17 \mu \mathrm{V}$, respectively. In terms of numerical values, the amplitude of N600 on the four categories from largest to smallest were Analogy, Metaphor, Simile, and Landscape.

Table 7 presents the overall result of MANOVA analysis of N600 for the category, anterior-central, and left-medial-right factors. The "left-medial-right" position factor has the main effect $(\mathrm{F}[2,30]=3.29, p=0.05$, $\varepsilon=0.77)$. Moreover, there was an interactions between the "category" $\mathrm{x}$ "anterior-central" position factors $(\mathrm{F}[3,45]=5.31, p=0.003, \varepsilon=0.54)$. Moreover, the "category" x "left-medial-right" position factors exhibit an interaction $(\mathrm{F}[6,90]=3.62, p=0.003, \varepsilon=0.52)$.

Further analysis on $t$-test for Landscape versus Metaphor discovered that only the N600 amplitude of the "right anterior" position was the highest $(\mathrm{t}[15]=2.08, p=0.053)$. Moreover, Landscape versus Analogy for $t$-test results

Table 4 The average amplitudes of N400 for simile, metaphor, analogy, and landscape (standard deviation of the mean in parentheses) (unit: $\mu \mathrm{V}$ )

\begin{tabular}{|c|c|c|c|c|c|c|c|}
\hline Category & Left anterior & Medial anterior & Right anterior & Left central & Medial central & Right central & All \\
\hline \multirow[t]{2}{*}{ Simile } & 2.19 & 2.20 & 2.44 & 1.10 & 0.98 & 1.31 & 1.70 \\
\hline & $(3.87)$ & (3.98) & $(3.91)$ & $(1.95)$ & $(2.26)$ & $(1.99)$ & $(2.99)$ \\
\hline \multirow[t]{2}{*}{ Metaphor } & 1.37 & 1.40 & 1.28 & 0.93 & 0.80 & 0.69 & 1.08 \\
\hline & $(2.71)$ & $(2.80)$ & $(2.52)$ & $(1.74)$ & $(1.86)$ & $(1.68)$ & $(2.22)$ \\
\hline \multirow[t]{2}{*}{ Analogy } & 2.29 & 2.36 & 2.62 & 1.33 & 1.42 & 1.26 & 1.88 \\
\hline & $(3.18)$ & $(3.16)$ & $(3.28)$ & $(1.99)$ & $(2.22)$ & $(2.06)$ & $(2.65)$ \\
\hline \multirow[t]{2}{*}{ Landscape } & 1.57 & 1.79 & 2.39 & 0.54 & 0.69 & 1.40 & 1.40 \\
\hline & $(2.73)$ & $(2.77)$ & $(2.97)$ & $(1.80)$ & $(1.95)$ & $(1.72)$ & $(2.32)$ \\
\hline
\end{tabular}

Table 5 The overall result of MANOVA analysis of N400 for the category, anterior-central, and left-medial-right factors

\begin{tabular}{|c|c|c|c|c|c|}
\hline Item & SS & $d f$ & MS & $\mathrm{F}$ & Sig \\
\hline Category & 35.74 & 3 & 18.91 & 0.84 & 0.44 \\
\hline Anterior-central & 87.44 & 1 & 87.44 & 5.93 & $0.03^{*}$ \\
\hline Left-medial-right & 5.06 & 2 & 3.65 & 2.84 & 0.16 \\
\hline Category $\times$ anterior-central & 5.54 & 3 & 1.85 & 1.03 & 0.39 \\
\hline Category $\times$ left-medial-right & 9.85 & 6 & 2.58 & 2.29 & 0.07 \\
\hline Anterior-central $\times$ left-medial-right & 0.30 & 2 & 0.23 & 0.34 & 0.62 \\
\hline Category $\times$ anterior-central $\times$ left-medial-right & 0.84 & 6 & 0.24 & 0.46 & 0.75 \\
\hline
\end{tabular}

${ }^{*} p<.05$

Table 6 The average amplitudes of N600 for simile, metaphor, analogy, and landscape (standard deviation of the mean in parentheses) (unit: $\mu \mathrm{V}$ )

\begin{tabular}{|c|c|c|c|c|c|c|c|}
\hline Category & Left anterior & Medial anterior & Right anterior & Left central & Medial central & Right central & All \\
\hline \multirow[t]{2}{*}{ Simile } & 0.81 & 0.78 & 0.85 & 0.47 & 0.45 & 0.44 & 0.63 \\
\hline & $(1.95)$ & $(2.11)$ & $(2.14)$ & $(1.27)$ & $(1.31)$ & $(1.11)$ & (1.65) \\
\hline \multirow[t]{2}{*}{ Metaphor } & 0.24 & 0.00 & 0.19 & 0.20 & -0.04 & 0.03 & 0.10 \\
\hline & $(2.18)$ & (2.33) & $(2.46)$ & $(1.09)$ & $(1.24)$ & $(1.21)$ & (1.75) \\
\hline \multirow[t]{2}{*}{ Analogy } & -0.05 & -0.11 & -0.05 & 0.13 & 0.07 & 0.20 & 0.03 \\
\hline & $(2.10)$ & $(2.23)$ & $(2.22)$ & $(1.21)$ & $(1.31)$ & $(1.24)$ & (1.72) \\
\hline \multirow[t]{2}{*}{ Landscape } & 1.65 & 1.71 & 2.09 & 0.31 & 0.41 & 0.86 & 1.17 \\
\hline & $(3.62)$ & (3.98) & $(4.11)$ & $(2.10)$ & $(2.36)$ & $(2.32)$ & (3.08) \\
\hline
\end{tabular}


Table 7 The overall result of MANOVA analysis of N600 for the category, anterior-central, and left-medial-right factors

\begin{tabular}{|c|c|c|c|c|c|}
\hline Item & SS & $d f$ & MS & $\mathrm{F}$ & Sig \\
\hline Category & 76.97 & 3 & 47.07 & 2.20 & 0.14 \\
\hline Anterior-central & 12.64 & 1 & 12.64 & 2.11 & 0.17 \\
\hline Left-medial-right & 1.89 & 2 & 0.95 & 3.29 & $0.05^{*}$ \\
\hline Category $\times$ anterior-central & 30.02 & 3 & 18.50 & 5.31 & $0.02^{*}$ \\
\hline Category $\times$ left-medial-right & 3.30 & 6 & 1.06 & 3.62 & $0.02^{*}$ \\
\hline Anterior-central $\times$ left-medial-right & 0.04 & 2 & 0.02 & 0.10 & 0.90 \\
\hline $\begin{array}{l}\text { Category } \times \text { anterior-central } \times \text { left- } \\
\text { medial-right }\end{array}$ & 0.27 & 6 & 0.12 & 0.47 & 0.65 \\
\hline
\end{tabular}

found that the N600 had the highest effect in the "left anterior" and "right anterior" positions $(\mathrm{t}[15]=2.14, p=0.05$ and $\mathrm{t}[15]=2.27, p=0.04$, respectively). Simile versus Metaphor for $t$-test results showed that the N600 had a significant difference in the "right central" position $(\mathrm{t}[15]=2.09$, $p=0.05$ ) (Table 8). Also, Simile versus Analogy for $t$-test results displayed the highest N600 effect in the "right anterior" position $(\mathrm{t}[15]=2.08, p=0.05)$. However, there was no significant difference in the N600 amplitudes for Landscape versus Simile and Metaphor versus Analogy. The results showed that the metaphor and analogy did have larger N600 amplitudes than Simile.

\section{Topography}

The Metaphor and Analogy respectively compare the stimuli of the Landscape, and both have significant N600 effects in the anterior area. Therefore, it can be observed from topography. Figure 10 shows the overall topography of the brain over the $600-800 \mathrm{~ms}$ time window. From the $640-720 \mathrm{~ms}$ time window, Metaphor and Analogy have a distinct N600 amplitude distribution (blue block) in the frontal region of the brain. Of these, the N600 effect from Metaphors in the 640-680 ms time window tends to manifest in the anterior region of the right side of the brain. Analogy has a more widely distributed N600 effect in the frontal lobe of both the left and right sides of the brain. However, Simile triggers no significant N600 effect. In addition, the amplitude of the images of the Landscape was positively reflected in the anterior region (red block), as was expected.

\section{Discussion}

This study investigated the impact of semantic relevance on the ability to comprehend images of the appearance and function of a product. Pictures showing Simile, Metaphor, and Analogy that corresponded to congruent, related, and incongruent semantic structures were presented and the amplitude of ERP was measured to compare the differences of these with an
Table 8 The overall result of paired sample t-test of N600 for simile, metaphor, analogy, and landscape

\begin{tabular}{|c|c|c|c|}
\hline Paired comparison & $T$ & $d f$ & Sig \\
\hline \multicolumn{4}{|c|}{ Landscape versus simile } \\
\hline Left anterior & 1.04 & 15 & 0.32 \\
\hline Medial anterior & 1.10 & 15 & 0.29 \\
\hline Right anterior & 1.44 & 15 & 0.17 \\
\hline Left central & -0.26 & 15 & 0.80 \\
\hline Medial central & -0.06 & 15 & 0.96 \\
\hline Right central & 0.81 & 15 & 0.43 \\
\hline \multicolumn{4}{|c|}{ Landscape versus metaphor } \\
\hline Left anterior & 1.65 & 15 & 0.12 \\
\hline Medial anterior & 1.92 & 15 & 0.07 \\
\hline Right anterior & 2.08 & 15 & $0.05^{*}$ \\
\hline Left central & 0.21 & 15 & 0.84 \\
\hline Medial central & 1.00 & 15 & 0.33 \\
\hline Right central & 2.01 & 15 & 0.06 \\
\hline \multicolumn{4}{|c|}{ Landscape versus analogy } \\
\hline Left anterior & 2.14 & 15 & 0.05 \\
\hline Medial anterior & 2.07 & 15 & 0.06 \\
\hline Right anterior & 2.27 & 15 & 0.04 \\
\hline Left central & 0.45 & 15 & 0.66 \\
\hline Medial central & 0.62 & 15 & 0.55 \\
\hline Right central & 1.25 & 15 & 0.23 \\
\hline \multicolumn{4}{|c|}{ Simile versus metaphor } \\
\hline Left anterior & 1.52 & 15 & 0.15 \\
\hline Medial anterior & 1.74 & 15 & 0.10 \\
\hline Right anterior & 1.62 & 15 & 0.13 \\
\hline Left central & 1.14 & 15 & 0.27 \\
\hline Medial central & 1.82 & 15 & 0.09 \\
\hline Right central & 2.09 & 15 & 0.05 \\
\hline \multicolumn{4}{|l|}{ Simile versus analogy } \\
\hline Left anterior & 1.86 & 15 & 0.08 \\
\hline Medial anterior & 1.86 & 15 & 0.08 \\
\hline Right anterior & 2.08 & 15 & 0.05 \\
\hline Left central & 1.45 & 15 & 0.17 \\
\hline Medial central & 1.31 & 15 & 0.21 \\
\hline Right central & 0.99 & 15 & 0.34 \\
\hline \multicolumn{4}{|c|}{ Metaphor versus analogy } \\
\hline Left anterior & 0.76 & 15 & 0.46 \\
\hline Medial anterior & 0.42 & 15 & 0.68 \\
\hline Right anterior & 0.66 & 15 & 0.52 \\
\hline Left central & 0.53 & 15 & 0.61 \\
\hline Medial central & -0.42 & 15 & 0.68 \\
\hline Right central & -0.93 & 15 & 0.37 \\
\hline
\end{tabular}

neutral image. It was found that the Metaphor image elicited a larger N600 amplitude in the right anterior region of the brain than the Landscape image and that the Analogy image induced a stronger N600 effect in 


Fig. 10 Topography: The distribution of brains in the $\mathrm{N600}$ effect for the Simile, Metaphor, Analogy, and Landscape images over the 600-800 ms
time window

the left anterior and right anterior regions than the Landscape image. However, the Simile image did not give a different N600 when compared to the neutral picture.

\section{Category consistency did not trigger the $\mathrm{N} 400$ response}

The Simile, Metaphor, and Analogy images did not trigger an N400 response, indicating that participants could identify these categories. In general, if pictures of different categories (such as books and hammers) were combined with pictures of the same category (such as zebras and white horses), a higher N400 was triggered [42-45]. Because the images in this study all belonged to the same category and there was thus no semantic conflict, it was expected that the N400 effect would not be generated. The participants in this study could detect the semantic relationship between the appearance of the product and its function, which made it easy for them to identify the image. However, once the participant was unable to understand the correlation between the stimulus, the late N600 slow wave was triggered.

\section{Incomprehensible images triggered an $\mathrm{N} 600$ effect}

The N600 is a waveform that is generated when semantic inconsistency is detected and the person makes an effort to deal with the inconsistency $[15,17]$. In this study, the ranking of the N600 amplitude from highest to lowest showed Analogy $>$ Metaphor $>$ Simile. This result is consistent with Lin and Huang's [1] study, indicating that the order of Metaphorical design interpretation was Simile $>$ Metaphor $>$ Analogy. This suggests that semantic structures using Metaphor and Analogy are not as easily understood as Simile. Simile is a direct design method that has no hidden meaning and gives clear indications of meaning [1]. Therefore, Simile is intuitive and easy to comprehend, and there is little semantic conflict. As expected, Simile triggered no N600 in this study. Metaphor and Analogy present ambiguous semantic structures, even if there is a slight semantic association between the product's appearance and function. Regardless of their semantics, which was related to introspection, those who did not have any background knowledge or understood the meaning of the images, needed to spend time trying to make sense of what they had seen after the viewing.

The results obtained in this study indicate that the images involving Metaphor and Analogy triggered the N600 response; thus, the participants were engaging in a process of comprehending the unfamiliar semantics. This contradicts previous research which has suggested that the use of Metaphor should trigger an N400 response [6, 7]. Other studies have confirmed that an N600 response 
could follow the second $\mathrm{N} 400$ response in the later period [16], indicating that N600 was a slow wave, and the mechanism of processing various semantic structures should have some commonality.

Some characteristics of Metaphor are similar to borrowed symbols (e.g., morphology, color, nature, etc.) [1]. The borrowed symbols could have been hidden in the expression of the appearance and therefore not easily noticeable. However, there is no direct correlation between Analogy and borrowed symbols [1] and any connection needs to be made by discerning common attributes and integrating these by means of past experience [46-48]. It could be seen that the level of semantic relevance and associations made in Analogy was more complex than that of discerning the meaning of Metaphor. Therefore, the N600 amplitude triggered by the image depicting Analogy was stronger than that for the image showing Metaphor.

\section{Differences in activity between related and incongruent semantic structures in various regions of the brain}

The N600 response to Analogy showed a wider distribution than it did to Metaphor in both the left- and right anterior regions. The response to Metaphor was mainly concentrated in the right anterior region. Research has shown that the N600 waves are most active in the frontal cortex [35-38]. This was confirmed by the results of this study which found that the N600 effect was induced in the anterior part of the brain. Because the images showing Metaphor offered unexpected concepts for ordinary items, interpreting these requires greater semantic processing and therefore, more intense activity and density in the brain [8]. The effect of images showing Metaphor was N600 distribution in the right anterior region of the brain while images depicting Analogy caused N600 distribution in the anterior area. This suggests that images depicting Analogy should require higher-level thinking and more complex semantic processing mechanisms than images depicting Metaphor $[49,50]$.

\section{Conclusion}

This study used images showing Simile, Metaphor, and Analogy to detect semantic associations between the appearance and function of a product and to measure ERP. ERP has the advantages of high-resolution measurement technology, which enables us to explore the cognitive process of participants in depth, and to compensate for the authenticity of the questions and responses of the questionnaires from an objective perspective. Simile, Metaphor, and Analogy were distinguished by the card-sorting method and classification according to semantic relevance: congruent, related and incongruent semantic structures. The results indicated by the N600 could prove that the relationship between pictures depicting Metaphor and Analogy and borrowed symbols was indirect or even not related, and both required semantic reassessment to be understood. However, the association between the pictures showing Simile and symbols was straightforward and did not require detailed interpretation.

The results detected significant ERP effects. Although the application of ERP has not been used much as a form of measurement in the design field, further use may be a way to help design research and expand new methods. The results of this study promoted the application of ERP methods to design research and helped physiology researchers understand more about the function of N600.

As was proposed, the main aims for the use of ERPs for this study were: (1) to improve the typicality of neutral stimuli. The content of the study using Landscape images as the neutral stimuli contained elements of views, people and animals, but the content of these pictures was complex. This may have overstimulated certain regions of the brain and triggered other emotions, resulting in higher ERP amplitudes. It is recommended that in the future, a gray image be used as the neutral stimulus, to reduce additional irritation. (2) It is also recommended that the variability of the stimuli in the N600 be considered. The same category of stimulus should be selected (such as chairs or lamps), and very different pictures in terms of appearance and structure be selected. This would make it easier to compare the differences in semantic relevance. (3) Participants with high sensitivity and understanding of the product should be selected. Although this study selected participants who had a background in design, there were cognitive differences in product design. It is recommended that that participants complete a fitness test (including thinking and sensitivity surveys) before the experiment and that suitable participants are selected. This would reduce cognitive differences. 
Appendix 1: The figurative products: (a) Simile, (b) Metaphor, and (c) Analogy stimulus

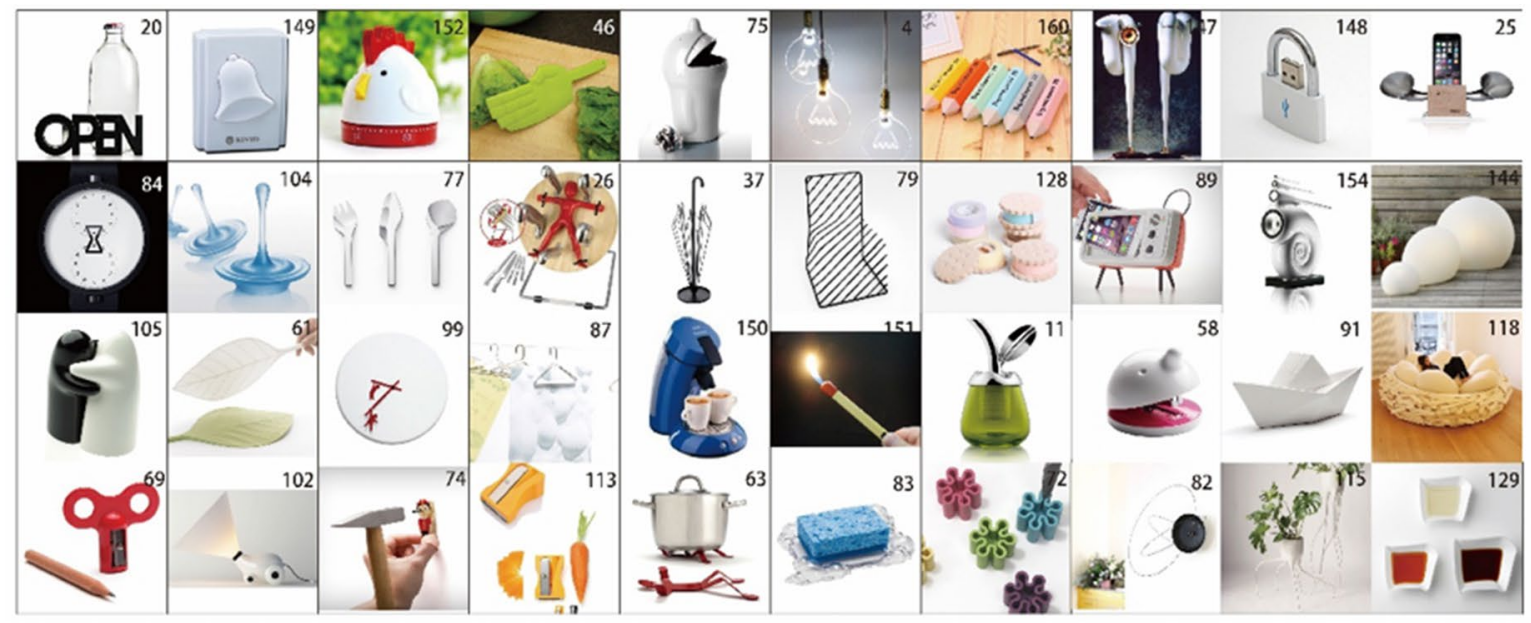

(a)

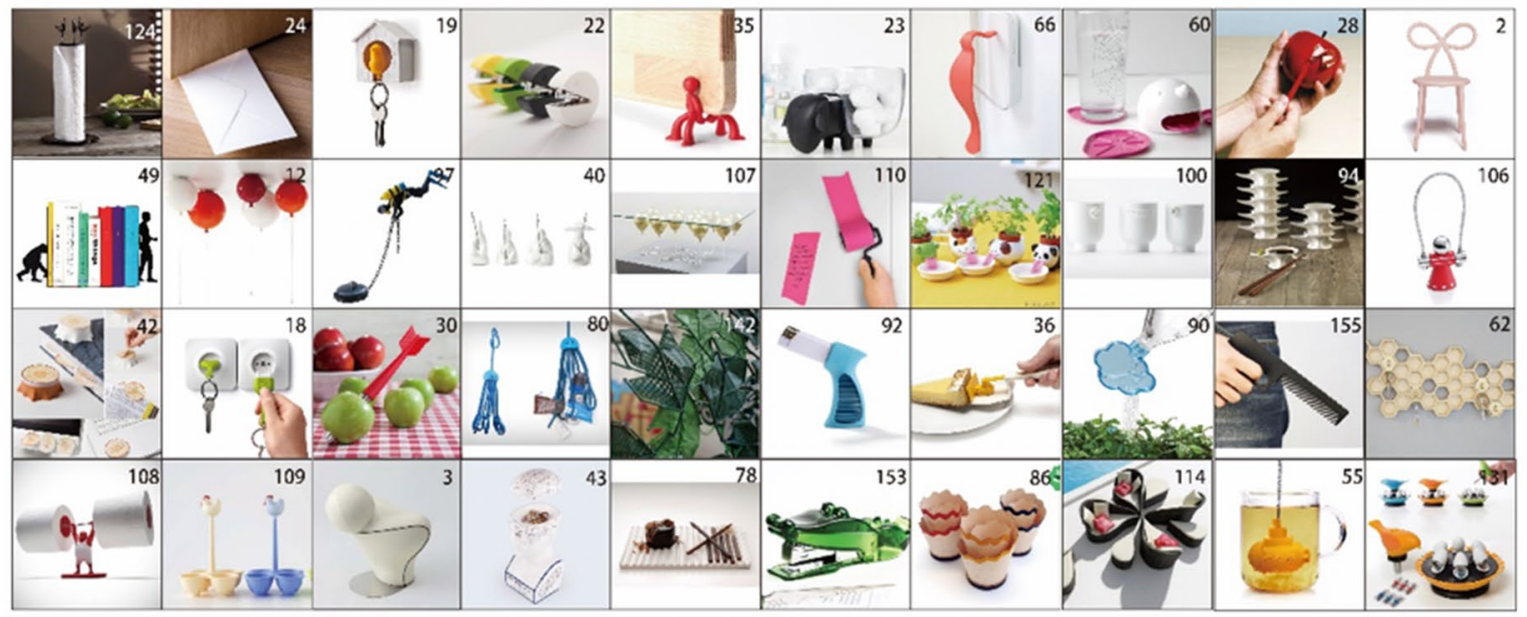

(b)

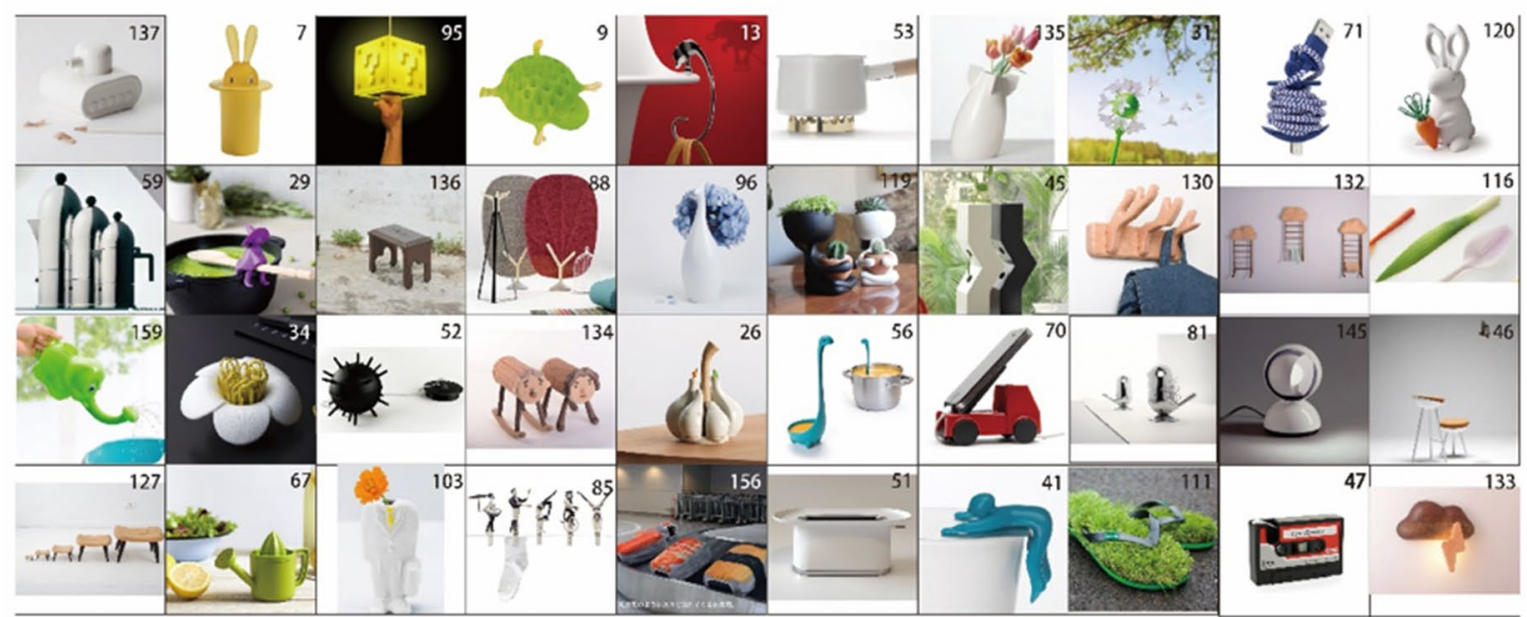




\section{Appendix 2: Picture-word matching combination} for the simile, metaphor, and analogy images

See Tables 9, 10, and 11.

Table 9 Picture-word matching combination of simile images

\begin{tabular}{|c|c|c|c|c|c|}
\hline $\begin{array}{l}\text { Prime word (Chinese/ } \\
\text { English) }\end{array}$ & & No. & $\begin{array}{l}\text { Prime word (Chinese/ } \\
\text { English) }\end{array}$ & & No. \\
\hline 開瓶器 & Bottle opener & 20 & 調味罐 & Spice jar & 105 \\
\hline 門鈴 & Doorbell & 149 & 隔熱熱 & Heat proof mat & 61 \\
\hline 鬧鐘 & Alarm clock & 152 & 時鐘 & Clock & 99 \\
\hline 廚具 & Kitchenware & 46 & 衣架 & Hanger & 87 \\
\hline 垃圾箱 & Trash can & 75 & 咖啡機 & Coffee maker & 150 \\
\hline 燈具 & Lamp & 4 & 打火機 & Lighter & 151 \\
\hline 靜止的 & Stationery & 160 & 澆水器 & Watering can & 11 \\
\hline 揚聲器 & Speaker & 147 & 訂書機 & Stapler & 58 \\
\hline 隨身碟 & Flash drive & 148 & 餐巾架 & Napkin holder & 91 \\
\hline 喇叭 & Loudspeaker & 25 & 沙發 & Sofa & 118 \\
\hline 時鐘 & Clock & 84 & 削鉛筆機 & Pencil sharpener & 69 \\
\hline 水塞 & Water plug & 104 & 燈具 & Lamp & 102 \\
\hline 餐具 & Tableware & 77 & 手工具 & Handle tool & 74 \\
\hline 廚具 & Kitchenware & 126 & 削鉛筆機 & Pencil sharpener & 113 \\
\hline 雨傘架 & Umbrella stand & 37 & 隔熱熱 & Heat proof mat & 63 \\
\hline 椅子 & Chair & 79 & 肥㿝盒 & Soap dish & 83 \\
\hline 膠帶 & Tape & 128 & 筆筒 & Pen holder & 72 \\
\hline 手機座 & Phone holder & 89 & 磁鐵 & Magnet & 82 \\
\hline 喇叭 & Loudspeaker & 154 & 花瓶 & Vase & 115 \\
\hline 燈具 & Lamp & 144 & 醬料碟 & Sauce dish & 129 \\
\hline
\end{tabular}

Table 10 Picture-word matching combination of metaphor images

\begin{tabular}{|c|c|c|c|c|c|}
\hline $\begin{array}{l}\text { Prime word (Chinese/ } \\
\text { English) }\end{array}$ & & No. & $\begin{array}{l}\text { Prime word (Chinese/ } \\
\text { English) }\end{array}$ & & No. \\
\hline 紙捲 & Paper roll & 124 & 便條 & Note & 42 \\
\hline 門擋 & Doorstop & 24 & 錀匙扣 & Key holder & 18 \\
\hline 錀匙扣 & Key holder & 19 & 廚具 & Kitchenware & 30 \\
\hline 訂書機 & Stapler & 22 & 夾子 & Clip & 80 \\
\hline 書擋 & Bookend & 35 & 書籤 & Bookmarks & 142 \\
\hline 文具 & Stationery & 23 & 打火機 & Lighter & 92 \\
\hline 門鈴 & Doorbell & 66 & 廚具 & Kitchenware & 36 \\
\hline 杯熱 & Coaster & 60 & 澆水器 & Watering can & 90 \\
\hline 削鉛筆機 & Pencil sharpener & 28 & 梳子 & Comb & 155 \\
\hline 椅子 & Chair & 2 & 儲物盒 & Storage box & 62 \\
\hline 書擋 & Bookend & 49 & 紙捲 & Paper roll & 108 \\
\hline 燈具 & Lamps & 12 & 蛋架 & Egg holder & 109 \\
\hline 水塞 & Water plug & 97 & 椅子 & Chair & 3 \\
\hline 夾子 & Clip & 40 & 存錢筒 & Piggy bank & 43 \\
\hline 桌子 & Table & 107 & 削鉛筆機 & Pencil sharpener & 78 \\
\hline 筆記 & Note & 110 & 訂書機 & Stapler & 153 \\
\hline 盆栽 & Pot culture & 121 & 筆筒 & Pen holder & 86 \\
\hline 調味罐 & Spice jar & 100 & 沙發 & Sofa & 114 \\
\hline 醬料碟 & Sauce dish & 94 & 廚具 & Kitchenware & 55 \\
\hline 錀匙扣 & Key holder & 106 & 手工具 & Handle tool & 131 \\
\hline
\end{tabular}


Table 11 Picture-word matching combination of analogy images

\begin{tabular}{|c|c|c|c|c|c|}
\hline $\begin{array}{l}\text { Prime word (Chinese/ } \\
\text { English) }\end{array}$ & & No. & $\begin{array}{l}\text { Prime word (Chinese/ } \\
\text { English) }\end{array}$ & & No. \\
\hline 削鉛筆機 & Pencil sharpener & 137 & 澆水器 & Watering can & 159 \\
\hline 牙籤罐 & Toothpick pot & 7 & 文具 & Stationery & 34 \\
\hline 燈具 & Lamp & 95 & 水塞 & Water plug & 52 \\
\hline 門擋 & Doorstop & 9 & 椅子 & Chair & 134 \\
\hline 掛鈎 & Hook & 13 & 調味罐 & Spice jar & 26 \\
\hline 隔熱熱 & Heat proof mat & 53 & 湯勺 & Ladle & 56 \\
\hline 花瓶 & Vase & 135 & 訂書機 & Stapler & 70 \\
\hline 檯燈 & Lamps & 31 & 文具 & Stationery & 81 \\
\hline 收線器 & Reel & 71 & 燈具 & Lamps & 145 \\
\hline 靜止的 & Stationery & 120 & 登子 & Stool & 146 \\
\hline 茶瑴 & Teapot & 59 & 発子 & Stool & 127 \\
\hline 固定器 & Holder & 29 & 榨汁機 & Juicer & 67 \\
\hline 発子 & Stool & 136 & 花瓶 & Vase & 103 \\
\hline 屏風 & Screen & 88 & 夾子 & Clip & 85 \\
\hline 花瓶 & Vase & 96 & 筷架 & Chopstick holder & 156 \\
\hline 盆栽 & Pot culture & 119 & 靜止的 & Stationery & 51 \\
\hline 花瓶 & Vase & 45 & 掛鈎 & Hook & 41 \\
\hline 掛鈎 & Hook & 130 & 拖鞋 & Flip flop & 111 \\
\hline 掛鈎 & Hook & 132 & 膠帶分配器 & Tape dispenser & 47 \\
\hline 餐具 & Tableware & 116 & 燈具 & Lamp & 133 \\
\hline
\end{tabular}

\section{Acknowledgements}

This research was supported by grants from the National Science Council, Taiwan to Ching-Yi Wang (110-2221-E-468-008). I am grateful to Chao-Yang Yang at Tatung University for the helpful comments on ERP experiment.

\section{Authors' contributions}

C-YW is responsible for the entire research planning, ERP data interpretation and article writing. $Y$ - $E \mathrm{~L}$ is responsible for collecting literature.

\section{Availability of data and materials}

The datasets generated and/or analysed during the current study are available in the [Google Docs] repository, [https://reurl.cc/7rzeo9].

\section{Declarations}

\section{Ethics approval and consent to participate}

The experimental standards of the study were approved by the China Medical University and Hospital Research Ethics Center of Taiwan (CRREC-109027). Written informed consent was obtained from all participants prior to participation.

\section{Consent to publish}

Not applicable.

\section{Competing interests}

I have no competing interests.

\section{Author details}

${ }^{1}$ Present Address: Department of Creative Product Design, Asia University, No. 500, Lioufeng Rd., Wufeng, Taichung City 41354, Taiwan. ²Department of Industrial Design, Tatung University, No. 40, Chungshan North Rd., Section 3, Taipei City 104, Taiwan.

Received: 15 July 2020 Accepted: 19 August 2021

Published online: 03 September 2021

\section{References}

1. Lin $\mathrm{MH}$, Huang CC. The logic of the figurative expressions and cognition in design practices. J Des. 2002;7(2):1-22.

2. Italian design. Casambrella 1710: Steel Progetti umbrella stand. 2018. https://www.italiandesigncontract.com/en/accessories/coatracks-umbre Ila-holders-dustbins-ashtrays-boxes/casambrella-1710-steel-progettiumbrella-stand/. Accessed 8 Aug 2017.

3. 83 Design. Original Works: Kataguruma. 2008. http://83design.jp/originalproducts/144/. Accessed 15 Aug 2017.

4. Mydesy. Product design: Peakco. 2014. https://pick.mydesy.com/archives/ 40454. Accessed 5 Aug 2017.

5. Raichle ME. Images of the Mind: studies with modern imageing techniques. Annu Rev Psychol. 1994;45:333-56.

6. Coulson S. Metaphor comprehension and the brain. In: Gibbs RW, editor. Metaphor and thought, 3rd ed. Cambridge: Cambridge University Press; 2008.

7. Coulson S, Van Petten C. Conceptual integration and Metaphor: an eventrelated potential study. Memory Cogn. 2002;30(6):958-68.

8. Ortiz MJ, Murcia MDG, Fernandez E. Brain processing of visual Metaphors: an electrophysiological study. Brain Cogn. 2017;113:117-24.

9. Arzouan Y, Goldstein A, Faust M. Dynamics of hemispheric activity during Metaphor comprehension: electrophysiological measures. Neuroimage. 2007;36(1):222-31.

10. Lai VT, van Dam W, Conant LL, Binder JR, Desai RH. Familiarity differentially affects right hemisphere contributions to processing Metaphors and literals. Front Hum Neurosci. 2015:9(44):1-10.

11. Pobric G, Mashal N, Faust M, Lavidor M. The role of the right cerebral hemisphere in processing novel Metaphoric expressions: a transcranial magnetic stimulation study. J Cogn Neurosci. 2008;20(1):170-81.

12. Schmidt GL, Seger CA. Neural correlates of Metaphor processing: the roles of figurativeness, familiarity and difficulty. Brain Cogn. 2009;71(3):375-86.

13. Chan Y-C, Chou T-L, Chen H-C, et al. Towards a neural circuit model of verbal humor processing: an fMRI study of the neural substrates of incongruity detection and resolution. Neuroimage. 2013:66:169-76. 
14. Feng Y-J, Chan Y-C, Chen H-C. Specialization of neural mechanisms underlying the three-stage model in humor processing: an ERP study. J Neurolinguist. 2014;32:59-70

15. Tu S, Cao X, Yun X, Wang K, Zhao G, Qiu J. A new association evaluation stage in cartoon apprehension: evidence from an ERP study. J Behav Brain Sci. 2014;4(2):75.

16. Shibata H, Gyoba J, Suzuki Y. Event-related potentials during the evaluation of the appropriateness of cooperative actions. Neurosci Lett. 2009:452(2):189-93.

17. Du X, Qin Y, Tu S, et al. Differentiation of stages in joke comprehension: evidence from an ERP study. Int J Psychol. 2013;48(2):149-57.

18. Coulson S, Lovett C. Handedness, hemispheric asymmetries, and joke comprehension. Cogn Brain Res. 2004;19(3):275-88.

19. Wang RWY, Kuo HC, Chuang SW. Humor drawings evoked temporal and spectral EEG processes. Soc Cogn Affect Neurosci. 2017;12(8):1359-76.

20. Samson AC, Hempelmann CF, Huber O, Zysset S. Neural substrates of incongruity-resolution and nonsense humor. Neuropsychologia. 2009:47:1023-33.

21. Samson AC, Zysset S, Huber O. Cognitive humor processing: different logical mechanisms in nonverbal cartoons-an fMRI study. Soc Neurosci. 2008;3:125-40.

22. Coulson S, Kutas M. Getting it: human event-related brain response to jokes in good and poor comprehenders. Neurosci Lett. 2001;316(2):71-4.

23. Marchewka A, Żurawski Ł, Jednoróg K, Grabowska A. The Nencki Affective Picture System (NAPS): introduction to a novel, standardized, wide-range, high-quality, realistic picture database. Behav Res Methods 2014:46(2):596-610.

24. Michałowski JM, Droździel D, Matuszewski J, Koziejowski W, Jednoróg K, Marchewka A. Set of Fear Inducing Pictures (SFIP): the development and validation in fearful and non-fearful individuals. Behav Res Methods. 2016:49(4):1407-19.

25. Riegel M, Żurawski $Ł$, Wierzba M, Moslehi A, Klocek $Ł$, Horvat M, Grabowska A, Michalowski J, Jednoróg K, Marchewka A. Characterization of the Nencki affective picture system by discrete emotional categories (NAPS BE). Behav Res Methods. 2016;48(2):600-12.

26. Wierzba M, Riegel M, Pucz A, Leśniewska Z, Dragan WŁ, Gola M, Jednoróg K, Marchewka A. Erotic subset for the Nencki Affective Picture System (NAPS ERO): cross-sexual comparison study. Front Psychol. 2015;6:1336.

27. Blanz V, Tarr MJ, Bülthoff HH. What object attributes determine canonical views? Perception. 1999;28(5):575-99.

28. DiCarlo JJ, Zoccolan D, Rust NC. How does the brain solve visual object recognition? Neuron. 2012;73(3):415-34

29. Luck SJ. An introduction to the event-related potential technique. Cambridge: MIT Press; 2005.

30. Picton TW, Bentin S, Berg P, Donchin E, Hillyard SA, Johnson R Jr, Miller GA, Ritter W, Ruchkin DS, Rugg MD, Taylor MJ. Guidelines for using human event-related potentials to study cognition: recording standards and publication criteria. Psychophysiology. 2000;37(2):127-52.

31. Mantini D, Perrucci MG, Del Gratta C, Romani GL, Corbetta M. Electrophysiological signatures of resting state networks in the human brain. Proc Natl Acad Sci. 2007:104(32):13170-5.

32. Chen $Y-T$, Chuang M-C. The study of tactile feeling and It's expressing vocabulary. Int J Ind Ergon. 2014;44(5):675-84.
33. Onton J, Westerfield M, Townsend J, Makeig S. Imaging human EEG dynamics using independent component analysis. Neurosci Biobehav Rev. 2006;30(6):808-22

34. Shackman AJ, McMenamin BW, Slagter HA, Maxwell JS, Greischar LL, Davidson RJ. Electromyogenic artifacts and electroencephalographic inferences. Brain Topogr. 2009;22(1):7-12.

35. Chen A, Luo Y, Wang Q, Yuan J, Yao D, Li H. Electrophysiological correlates of category induction: PSW amplitude as an index of identifying shared attributes. Biol Psychol. 2007;76:230-8.

36. Qiu J, Li H, Chen AT, Zhang QL. The neural basis of analogical reasoning: an event-related potential study. Neuropsychologia. 2008:46:3006-13.

37. Zhao M, Meng HS, Xu ZY, Du FL, Liu T, Li YX, Chen FY. The neuromechanism underlying verbal analogical reasoning of Metaphorical relations: an event-related potentials study. Brain Res. 2011;1425:62-74.

38. Zhao M, Xu ZY, Liu T, Du FL, Li YX, Chen FY. The Neuromechanism underlying language analogical reasoning: evidence from an ERP study. Acta Psychol Sin. 2012;44:711-9.

39. Krawczyk DC. The cognition and neuroscience of relational reasoning. Brain Res. 2012;1428:13-23.

40. Eddy MD, Holcomb PJ. Electrophysiological evidence for size invariance in masked picture repetition priming. Brain Cogn. 2009;71:397-409.

41. Lin MH, Wang CY, Cheng SK, Cheng SH. An event-related potential study of semantic style-match judgments of artistic furniture. Int J Psychophysiol. 2011;82:188-95.

42. Mathalon DH, Roach BJ, Ford JM. Automatic semantic priming abnormalities in schizophrenia. Int J Psychophysiol. 2010;75:157-66

43. Bobes MA, Lei MA, Ibáñez S, Yi H, Valdes-Sosa M. Semantic matching of pictures in schizophrenia: a cross-cultural ERP study. Biol Psychiat. 1996:40:189-202

44. Guerra S, Ibanez A, Martin M, Bobes MA, Reyes A, Mendoza R, Bravo T, Dominguez M, Sosa MV. N400 deficits from semantic matching of pictures in probands and first-degree relatives from multiplex schizophrenia families. Brain Cogn. 2009;70(2):221-30.

45. Hamm JP, Johnson BW, Kirk IJ. Comparison of the N300 and N400 ERPs to picture stimuli in congruent and incongruent contexts. Clin Neurophysiol. 2002:113:1339-50

46. Changquan L, Li J, Chen A, Qiu J, Chen J, Li H. Event-related potential responses to letter-string comparison analogies. Exp Brain Res. 2015;233(5):1563-1573.

47. Jani NG, Levine DS. A neural network theory of proportional analogymaking. Neural Netw. 2000;13:149-83

48. Wendelken C, Nakhabenko D, Donohue SE, Carter CS, Bunge SA. "Brain is to thought as stomach is to?": investigating the role of rostrolateral prefrontal cortex in relational reasoning. J Cogn Neurosci. 2008;20(4):682-93.

49. Gentner D, Forbus K. Computational models of analogy. WIREs Cognit Sci. 2011:2:266-76.

50. Gentner D, Smith L. Analogical reasoning. In: Ramachandran VS, editor. Encyclopedia of human behavior. 2nd ed. Oxford: Elsevier; 2012. p. 130-6.

\section{Publisher's Note}

Springer Nature remains neutral with regard to jurisdictional claims in published maps and institutional affiliations.

Ready to submit your research? Choose BMC and benefit from

- fast, convenient online submission

- thorough peer review by experienced researchers in your field

- rapid publication on acceptance

- support for research data, including large and complex data types

- gold Open Access which fosters wider collaboration and increased citations

- maximum visibility for your research: over 100M website views per year

At $\mathrm{BMC}$, research is always in progress.

Learn more biomedcentral.com/submissions 